\title{
Does Investing in Renewable Energy Sources Contribute to Growth? A Preliminary Study on Greece's National Energy and Climate Plan
}

\author{
Dimitrios Stamopoulos ${ }^{1}$ (D), Petros Dimas ${ }^{1}$ (D) , Ioannis Sebos ${ }^{2, *(\mathbb{D})}$ and Aggelos Tsakanikas ${ }^{1}$ \\ 1 Laboratory of Industrial and Energy Economics, National Technical University of Athens, \\ 15780 Zografou, Greece; dstamopoulos@mail.ntua.gr (D.S.); petrdimas@chemeng.ntua.gr (P.D.); \\ atsaka@central.ntua.gr (A.T.) \\ 2 School of Chemical Engineering, National Technical University of Athens, 15780 Zografou, Greece \\ * Correspondence: isebos@mail.ntua.gr; Tel.: +30-210-772-3135
}

Citation: Stamopoulos, D.; Dimas, P.; Sebos, I.; Tsakanikas, A. Does Investing in Renewable Energy Sources Contribute to Growth? A Preliminary Study on Greece's National Energy and Climate Plan. Energies 2021, 14, 8537. https:// doi.org/10.3390/en14248537

Academic Editor: George Halkos

Received: 12 November 2021 Accepted: 13 December 2021 Published: 17 December 2021

Publisher's Note: MDPI stays neutral with regard to jurisdictional claims in published maps and institutional affiliations.

Copyright: (c) 2021 by the authors. Licensee MDPI, Basel, Switzerland. This article is an open access article distributed under the terms and conditions of the Creative Commons Attribution (CC BY) license (https:/ / creativecommons.org/licenses/by/ $4.0 /)$.

\begin{abstract}
As more economies are transitioning away from fossil fuels for their electricity production and towards greener alternatives, many socioeconomic implications of this shift remain actively debated. The present paper attempts to assess the economic impact of investments in renewable energy sources (RESs) for Greece and whether the broader effects of this transition can offset the negative impact that will occur due to the targeted phase-out of lignite plants by 2028, which constitute the predominant power source for Greece. Our methodological approach builds on inputoutput analysis and the creation of composite RES industries for the estimation of the net effects of a series of monetary shocks that correspond to Greece's phase-out investment plan, utilizing the most recent national input-output tables and satellite structural business statistics. We focus on the structural effects of these shocks on a series of socioeconomic indicators, including GDP, employment, wages, government income (through taxes), and capital formation. The results indicate that even though lignite power production still provides a significant contribution to the Greek economy, investing in renewables presents a significant opportunity for value added and job creation.
\end{abstract}

Keywords: input-output analysis; renewables; lignite phase-out; European Green Deal; economic multipliers; energy policy

\section{Introduction and Scope}

As the world is headed towards the first quarter of the 21st century, issues related to climate change and the role of humanity in it are more relevant than ever. More people live on the earth than ever before, and are constantly increasing the demand for products, services, and energy, exerting significant pressure on existing production and energy networks. At the same time, the exponential growth of carbon dioxide $\left(\mathrm{CO}_{2}\right)$ and other greenhouse gas (GHG) emissions stemming from the increase in production activity and capacity were already deemed unsustainable in the last century, and policies at both the national and international level were introduced to guide the transition to "greener" alternatives for energy production [1,2].

Accordingly, at the EU level the European Green Deal provides a setting of guidelines and frameworks for the transformation of the EU into a modern, resource-efficient, and climate-neutral economy. Within this context, two of the main pillars include the transition to no-net emissions of GHGs by 2050 and the decoupling of economic growth from the usage of resources. Focusing specifically on the energy sector, the decarbonization of the EU's energy system has been brought to the epicenter of relevant strategies as it accounts for approximately 77\% of the EU's overall GHG emissions in 2019, with the power sector contributing approximately $20 \%$ [3]. It is therefore critical for the success of the overall strategic framework for the energy sector to properly implement a set of well-devised 
actions to achieve the 55\% GHG emission reduction threshold by 2030 (compared with 1990 levels). To meet this demanding goal and the overall energy and climate targets by 2030, the EU member states were asked by the European Commission to develop and establish their individual National Energy and Climate Plans (NECPs), which outline each country's agenda, action items, and appropriate measures to address specific areas that include energy efficiency, increased shares of renewable energy sources (RESs), GHG emission reduction, research, and innovation [4].

One critical element of NECPs is the promotion of RES participation in the energy production mix and broader interventions for more efficient energy usage. At the same time, they include many important aspects of the entire energy planning for the future, such as energy storage, advances in mobility and transportation, power grid improvements, weatherization of buildings, and research activities for energy and the climate. Another linked major component relates to the included provisions for an eventual phase-out of less environmentally friendly energy production methods (mainly coal/lignite and crude oil derivatives) towards RESs and low carbon fuels, such as natural gas, to be used as transition fuels until the full deployment of RESs. This transition has consistently been an attractive field for both private and public investment, and significant efforts have been put forward to develop each country's decarbonization plans based on its own relative strengths, geographical characteristics, and economic competencies. Such actions require specialized information on the fundamental structure of the economy and the relative importance of energy-related activities within it. As these can vary widely even among neighboring and similar EU member states, the approaches that will yield the most relevant implications should focus on specific regions and their characteristics in terms of production structure, employment dependency on carbon-intensive production, and overall contributions of investment in RESs to the value components of the aggregate economy.

Building on these positions, the scope of this study is twofold. First, we aim to quantify the resulting economic structural effects of investment in energy production from RESs, and second, we aim to investigate whether these effects can offset the negative impact of shifting equivalent amounts of subsidies away from fossil-fuel-related industries. Our study is focused on Greece, a Mediterranean EU economy with high potential for RES harnessing due to its geographical merits and climate conditions but also with a strong historical dependence on carbon-intensive energy production, with a (until recently) state-controlled single-energy producer operating lignite-fueled power plants and being a prominent employer in many rural regions. Greece has set ambitious environmental goals regarding its energy production (NECP), including the total phase-out of these lignite plants by 2028 [5]. However, its decade-long struggle with the aftereffects of the 2008 economic crisis, followed by economic disruption from the COVID-19 pandemic, has exacerbated problems related to energy production and pricing, placing additional strains on the market supply networks and the disposable income of households and creating challenging socioeconomic conditions that may well affect the progress and feasibility of the energy transition plan. To this end, we develop an input-output framework to allocate the planned RES investments from Greece's NECP to corresponding economic sectors through a composite industry approach. We then utilize input-output modelling to quantify the structural effects of the RES investment plan in the Greek economy. Overall, we find significant contribution to gross domestic product (GDP), wages, employment, and capital asset formation in a 10-year frame (2020-2030). These positive effects are mainly driven in their overwhelming majority by investments in solar and wind power generation.

The remainder of this paper is structured as follows. In Section 2, we discuss the theoretical background of this study. Section 3 presents the methodology and our data sources, while Section 4 presents and discusses the empirical results. Finally, Section 5 concludes the paper and provides remarks for future research. 


\section{Literature Review}

The promotion of RES participation in the energy production mix and the broader interventions for more efficient energy usage have been at the core of environmental and climate-related policies, attracting attention by a significant body of literature that utilizes different methodologies to quantify energy, environmental and socioeconomic outcomes, and related implications. Focusing on the latter dimension, a growing body of literature has been concerned with exploring the economic impact of RES consumption, different investment plans for RES deployment, and energy efficiency. These studies have adopted a large and diversified set of methodological frameworks and empirical tools in their attempts to quantify the macroeconomic effects of RESs, focusing their efforts on two main economic figures, GDP and employment effects.

Early studies adopted an analytical approach, using bottom-up estimates based on regional, industry, and/or technology case studies and providing evidence of the direct effects of a given investment on the industry or the region that absorbs it [6-9]. These studies predominantly focus on employment implications and are confined to the level of analysis of their given case study. As a result, they are not able to capture the additional structural effects of a RES investment at the economy level $[9,10]$. The most common empirical instruments deployed in these types of studies are employment ratios or factors, which are calculated based on the expected capacity of a specific type of technology or a set of technologies examined, producing a ratio of employment (jobs or full-time job equivalents) per energy unit (e.g., kilowatt). These ratios can be fixed or time varying over a specific period and are usually derived by common sources for different studies (e.g., [11,12]). Although they are "easy-to-use instruments", they should be treated with caution and consolidated with additional information [9].

Another line of research is preoccupied with top-down modelling applications [7]. These applications can be categorized into two wider categories, which include econometric applications and computable general equilibrium (CGE) models (either general or partial). Between the two, econometric applications are more popular in relevant literature and follow a different direction compared with analytical studies, as they focus on the effects of RES proxies on growth using gross output or GDP indicators in more aggregate applications. In this line, several studies built their modelling approach based on extended production functions, where output (or GDP) is explained as a function of the traditional factors of production (labor, capital, and in some cases technology) extended by a RES approximation variable, usually the aggregate RES consumption and/or the share of RES consumption to the energy mix. A typical methodological procedure includes the deployment of advanced estimation approaches on time series and/or panel applications with case studies on specific countries (e.g., [13]) or across different economies that provide the appropriate data availability (as in [14-16]). The common empirical finding among these studies is the strong and statistically significant effect of RES consumption on economic growth, which is in turn utilized to bridge environmental and economic benefits.

Other studies are preoccupied with econometric applications that go beyond the level of traditional production functions and adopt diversified ad hoc approaches to capture the effects of RESs on growth across countries while also considering additional economic and environmental factors that may affect this relationship. Menegaki [17] studied the effects of RES consumption on GDP for a panel of 27 European economies in the period of 1997-2007, introducing GHG emissions into the specifications as an environmental factor and taking into account employment at the country level as well. Surprisingly, the results of this study did not unveil a strong and statistically significant positive relationship between GDP and RES consumption of production-function-based approaches but did provide interesting insights that relate to the regional characteristics of a sample of countries and the early stages of development of energy markets and energy policies in the EU. As energy policies in the EU progressed and the energy market evolved towards decarbonization and renewables, more recent studies focused on EU documenting a strong and positive relationship between GDP and RES consumption [18-21], while some studies highlighted 
differences in effects among countries with different levels of development (as depicted by their GDP) [22] but also with different energy profiles [23]. Country-specific characteristics are critical when examining the economic effects of RESs, and although country-specific case studies can provide useful insights [24,25], econometric applications are unable to distinguish between direct and indirect effects of RES consumption and promotion that relate to the structure of the economy and the domestic energy market. Another significant deficiency of econometric models relates to their data needs and the fact that common practice indicates the use of a time series of historical data regarding the consumption of RESs, while future policy interventions and planned investment in RESs in the economy cannot be properly approximated by a single (or a series) variable, nor can they be easily configured into a model specification.

A more suitable methodological framework for modelling policy implications that can assess both the direct and indirect effects of an investment project or plan on key economic indicators and naturally is applicable in the analysis of environmental and energy policy interventions is input-output (I-O) analysis [26,27]. More specifically, I-O models describe the production linkages within a given economic system, which includes different economic sectors (industries) and final users. These linkages are depicted in inputoutput tables (IOTs), which provide a coherent illustration of the exchange of intermediate goods and services among different industries for production purposes in the form of interindustry monetary transactions and information regarding the monetary market transactions between the various industries and final users of their products (including various final-use categories, such as households, government, and capital formation). I-O models provide a proper macroeconomic setting for the calculation of a series of structural effects that occur due to external monetary shocks (such as multi-industry investment plans) allocated to different industries of a given national economy and thus qualify as a proper empirical tool for policy analysis [26]. In detail, there are three types of effects that are computable through I-O analysis: (i) the direct effects that relate to the economic implications on the industry that absorbs the shock (e.g., increase in value added and/or employment), (ii) the indirect effects caused on the rest of the industrial sectors that provide the production inputs of the industry and absorb its output, and (iii) the induced effects that result from the stimulation of household income (increase in wages and salaries) that relates to the external shock in the economy.

Several studies have adopted the I-O framework to quantify the impact of clean energy promotion and growth, providing evidence of positive macroeconomic structural effects of RES and EE investment on different socioeconomic indicators of interest and different economies $[7,27-34]$. For comprehensive reviews regarding studies that deployed I-O frameworks to quantify the structural effects of RES and EE and a comparative analysis of alternative empirical approaches, the interested reader could turn to [6,9]. Most of these studies focused on the impact of RES-related investments on employment, providing evidence of the importance of the direct effect of "green jobs" (i.e., employment on the RESs and other clean energy sectors [30]) and the indirect effects of employment stimulation on the rest of the industrial sectors from sustainable investment projects. They examined a large variety of shocks and policy interventions, and although a common finding indicates that investment in RESs provides greater macroeconomic benefits compared with conventional energy production technologies (e.g., based on fossil fuels (FF for short)), their results diverged in terms of the magnitude of each impact dimension and the specific technology that provides the bigger benefits, with the differences among them relating to the structure of the underlying economy that was examined.

However, I-O models also present some limitations that mainly relate to their static nature, as they describe a "snapshot" of the production structure of the economy on a given year, depicting fixed production linkages. Furthermore, national IOTs for most economies are not readily available on an annual basis and are usually published with a significant delay. For example, the Hellenic Statistical Authority publishes updated versions of the Greek national IOT on a 5-year basis and with a significant delay between the publication 
date and the reference year of the IOT. This is a common practice across various statis-tical agencies in the EU following respective publication guidelines by Eurostat [35]. A possible remedy to these shortcomings is the development of dynamic I-O models that use specific benchmarks to converge data from an existing (and probably outdated) IOT, but these types of approaches can face significant criticism regarding the selection of the appropriate convergence benchmarks [10]. Other extensions that aim to integrate missing economic transactions and more detailed and disaggregated information into the traditional model are social accounting matrix models (SAMs) [36,37] and integrated CGE models [38,39], both of which can also be treated as dynamic in nature. SAM and CGE models provide coherent frameworks and the proper structural setting to analyze the implications of energy policies by configuring them into different types of effects but also face significant problems that relate to data availability (mostly for SAM applications) and increased computational complexity (for CGE models).

For the purposes of this study, we develop our methodological framework based on an I-O model application. Despite its relative shortcomings, we select the I-O model as it provides significant merits that relate to minimum data requirements (in our case, data are already available from the Greek National Accounts of the Hellenic Statistical Authority), simple and replicable computational procedure [30], comparable results with other studies in the field $[7,27,30,32,33]$, and straightforward interpretation of the calculated structural effects of Greece's lignite phase-out investment plan. In the following section, we thoroughly discuss our methodology and details regarding the set of assumptions needed to integrate RES industries and the respective investment plans within the I-O model.

\section{Methodology}

In this section, we describe our methodological approach and the respective data sources. Summarizing our framework, we develop a 4-part methodological approach. At first, we estimate the required investment in RESs for Greece to achieve the 2030 goal of installed capacity, drawing data from the Greek NECP [5]. In the second stage, we retrieve the latest IOT for Greece (2015) along with key satellite structural economic data from the Hellenic Statistical Authority (ELSTAT). We then compile information about the breakdown of required investment in the appropriate economic sectors and integrate it with the satellite structural economic indicators in the third stage. In the fourth and final stage, we employ the I-O modelling framework to estimate the structural effects of investment in RESs in terms of multiplier potential, as well as their ability to offset the negative effects of shifting investment and subsidies away from lignite and oil power generation. A schematic representation of the different stages of our methodology is presented in Figure 1.

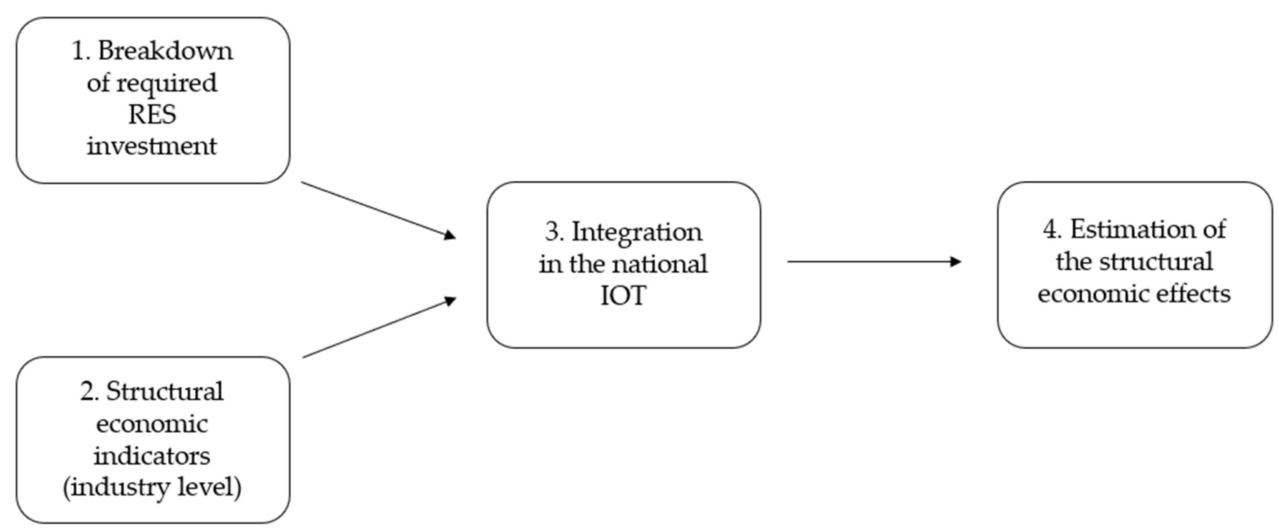

Figure 1. A simplified overview of the methodological framework.

The following subsections provide more detailed information regarding each stage of our methodology. 


\subsection{Estimation of Required Investments in RESs}

The Greek NECP contains detailed information about the transition to a more RESintensive production mix by 2030, including specific milestones for installed energy production capacity and cost estimates by type and unit of power (see Tables 1 and 2).

Table 1. Cost change estimates for the deployment of RES plans in Greece per type and KW of installed capacity for 2020-2030.

\begin{tabular}{cccccc}
\hline Cost $(\boldsymbol{\epsilon} / \mathbf{K W})$ & $\mathbf{2 0 2 0}$ & $\mathbf{2 0 2 2} \mathbf{2 0}^{*}$ & $\mathbf{2 0 2 5}$ & $\mathbf{2 0 2 7}$ & $\mathbf{2 0 3 0}$ \\
\hline Wind & 1161 & 1079 & 997 & 929 & 860 \\
Solar PV park & 552 & 513 & 473 & 447 & 420 \\
Solar PV roof & 1019 & 963 & 907 & 862 & 816 \\
Solar CSP storage & 4100 & 3980 & 3860 & 3615 & 3370 \\
Comp. solar ** & 1556 & 1492 & 1428 & 1342 & 1257 \\
Geothermal & 4400 & 4400 & 4400 & 3900 & 3400 \\
Hydro & 1900 & 1900 & 1900 & 1900 & 1900 \\
Biomass big & 2700 & 2700 & 2700 & 2700 & 2700 \\
Biomass small & 3500 & 3500 & 3500 & 3500 & 3500 \\
Biogas & 4350 & 4350 & 4350 & 4350 & 4350 \\
Comp. biomass *** & 3850 & 3850 & 3850 & 3850 & 3850 \\
\hline
\end{tabular}

Source: Adaptation from the Greek NECP [5]. Notes: ${ }^{*}$ Values for 2022 and 2027 are interpolated; ${ }^{* *}$ composite solar cost comprising 50\% PV parks, $25 \%$ PV roofs, and 25\% solar CSPs with storage; ${ }^{* * *}$ composite biomass cost comprising $50 \%$ biogas and $25 \%$ small and $25 \%$ big biomass plants.

Table 2. Plans for energy generation capacity mix in Greece by type and GW of installed capacity for 2020-2030.

\begin{tabular}{cccccc}
\hline Capacity $(\mathbf{G W})$ & $\mathbf{2 0 2 0}$ & $\mathbf{2 0 2 2}$ & $\mathbf{2 0 2 5}$ & $\mathbf{2 0 2 7}$ & $\mathbf{2 0 3 0}$ \\
\hline Lignite & 3.9 & 2.9 & 0.7 & 0.7 & - \\
Oil & 1.9 & 1.7 & 1.0 & 1.0 & 0.3 \\
Gas & 5.2 & 6.0 & 6.9 & 6.9 & 6.9 \\
Total FF & $\mathbf{1 1}$ & $\mathbf{1 0 . 6}$ & $\mathbf{8 . 6}$ & $\mathbf{8 . 6}$ & $\mathbf{7 . 2}$ \\
Bioenergy & 0.1 & 0.1 & 0.1 & 0.2 & 0.3 \\
Hydro & 3.4 & 3.7 & 3.8 & 3.9 & 3.9 \\
Wind & 3.6 & 4.2 & 5.2 & 6.0 & 7.0 \\
Solar & 3.0 & 3.9 & 5.3 & 6.3 & 7.7 \\
Geothermal & - & - & - & 0.1 \\
Total RES & $\mathbf{1 0 . 1}$ & $\mathbf{1 1 . 9}$ & $\mathbf{1 4 . 4}$ & $\mathbf{1 6 . 4}$ & $\mathbf{1 9 . 0}$ \\
Total & $\mathbf{2 1 . 1}$ & $\mathbf{2 2 . 5}$ & $\mathbf{2 3 . 0}$ & $\mathbf{2 5 . 0}$ & $\mathbf{2 6 . 2}$ \\
\%RES in Total & $48 \%$ & $53 \%$ & $63 \%$ & $66 \%$ & $73 \%$ \\
\hline
\end{tabular}

Source: Adaptation from the Greek NECP [5].

The associated costs per MW of installed capacity are consistently and gradually subsiding for solar, wind, and geothermal energy plants. For example, $1 \mathrm{KW}$ of contribution to energy generation capacity from solar CSPs is expected to be $17.8 \%$ less costly than it is now. This could be attributed to the advances in the technology of each field that enable more design flexibility with respect to RES participation in the energy mix, as they are becoming less cost intensive and more economically feasible.

As seen in Table 2, the phase-out of lignite power generation will materialize by 2028, while power production from oil will be drastically reduced. There is, however, a slight increase in the relative importance of gas in the energy generation capacity due to its use as a transition fuel towards eventual net-zero emissions by 2050 .

We estimate the amount of required new investment for each energy type $(e)$ and year $(t)$ in the following manner (Equation (1)):

$$
\Delta \mathrm{C}_{e, t}=\text { Capacity }_{e, t} \widehat{\operatorname{Cos}}_{e, t}-\text { Capacity }_{e, t-1} \widehat{\operatorname{Cost}}_{e, t-1}
$$

where $\Delta \mathrm{C}_{e, t}$ is the cost for energy type $(e)$ and time period $(t)$ that is required for the increase in installed power generation capacity of $(e)$, which will have to be covered by a corresponding investment initiative in the output of the composite industries that can 
realize this increase. The hat accent indicates that the monetary cost is expressed per unit of power generation.

\subsection{Short Note on the Input-Output Framework of Analysis}

I-O models are widely considered one of the most suitable frameworks for the exploration of production relationships in an economy, first introduced by Leontief in his seminal work, which earned him a Nobel Prize in Economics [40]. They can provide insights at the regional, national, and international level (through multiregional IOTs) and can also be modified to capture the interrelations of local economic systems. I-O frameworks are typically subjected to some inherent limitations that mainly relate to three core assumptions about the structure and nature of the economy that they describe. First, each single product is assigned to the production output of one specific industry, with no shared production across them; second, they do not account for production scaling effects (economies of scale) (i.e., output levels are linearly associated with the levels of the required inputs); and third, they assume that all production output is eventually consumed within the economic system that the IOT describes [26]. Despite these limitations, I-O models have consistently been proven to be a significant tool for economic and industrial policy and have provided the empirical foundations for comparative analysis between different industries and economies [26]. The aforementioned constraints that accompany the use of I-O models along with all the relationships they describe are formulated into properly formatted IOTs, which usually are derived from supply and use tables and are made public every few years from the relevant authorities, ranging considerably in geographical scope, accounting standards, industrial classification, and aggregation levels. A typical—albeit significantly simplified — format for a national IOT is presented below in Table 3 (single economy, K number of industries).

Table 3. Input-output table for a national economy of $\mathrm{K}$ industries.

\begin{tabular}{|c|c|c|c|c|c|c|c|c|c|}
\hline & \multicolumn{5}{|c|}{ Intermediate Consumption } & \multicolumn{3}{|c|}{ Final Uses } & \multirow{2}{*}{ Total Use } \\
\hline & Industry & $I_{1}$ & $I_{2}$ & {$[\ldots]$} & $I_{K}$ & $F_{1}$ & {$[\ldots]$} & $F_{N}$ & \\
\hline \multirow{4}{*}{$\begin{array}{l}\text { Intermediates } \\
\text { Supply }\end{array}$} & $I_{1}$ & $x_{1,1}$ & $x_{1,2}$ & {$[\ldots]$} & $x_{1, K}$ & $f_{1,1}$ & {$[\ldots]$} & $f_{1, N}$ & $Y_{1}$ \\
\hline & $I_{2}$ & $x_{2,1}$ & $x_{2,2}$ & {$[\ldots]$} & $x_{2, K}$ & $f_{2,1}$ & {$[\ldots]$} & $f_{2, N}$ & {$[\ldots]$} \\
\hline & {$[\ldots]$} & {$[\ldots]$} & {$[\ldots]$} & {$[\ldots]$} & {$[\ldots]$} & {$[\ldots]$} & {$[\ldots]$} & {$[\ldots]$} & {$[\ldots]$} \\
\hline & $I_{K}$ & $x_{K, 1}$ & $x_{K, 2}$ & {$[\ldots]$} & $x_{K, K}$ & $f_{K, 1}$ & {$[\ldots]$} & $f_{K, N}$ & $Y_{N}$ \\
\hline \multicolumn{2}{|c|}{ Value Added } & $V A_{1}$ & {$[\ldots]$} & {$[\ldots]$} & $V A_{K}$ & & & & \\
\hline \multicolumn{2}{|c|}{ Gross Output } & $T_{1}$ & $T_{2}$ & & $T_{K}$ & & & & \\
\hline
\end{tabular}

Most published IOTs follow the format above to some considerable extent. The upper left quartile of the table contains the $(K \times K)$ sized $X$ matrix of intermediate consumption, with each individual element $x_{i, j}$ denoting the monetary value of goods and services that are produced by the $i_{t h}$ sector and consumed by the $j_{t h}$ sector for production purposes (bold font for characters denotes a matrix or vector (e.g., $A$ ), whereas regular font indicates a number or a matrix element (e.g., y)). Similarly, on the right block, each $f_{i, j}$ element denotes the amount of output from the $i_{\text {th }}$ sector that is used for final consumption type $j$. VA is a $(1 \times K)$ vector of the value added, and $Y, T$ are $(K \times 1)$ and $(1 \times K)$ vectors containing the total gross output and the total requirements for inputs per sector. Overall, an IOT contains a significant amount of information and a snapshot of the production network of the economic system that it describes for a specific year.

From this information, the input requirements for production per unit of output can be estimated and gathered into a matrix form (often called matrix of technological coefficients) as $A=X \hat{Y}^{-1}$, and then can be postmultiplied by an appropriate vector of demand to estimate the required changes in output as $\Delta \boldsymbol{X}=(\boldsymbol{I}-\boldsymbol{A})^{-1} \Delta \boldsymbol{Y}$. The expression $(\boldsymbol{I}-\boldsymbol{A})^{-1}$ is the wellknown Leontief inverse matrix. For the estimation of multiplier effects (MLTs) by type per 
unit of increase in the final demand in each synthetic industry, an appropriate vector (aspect of interest divided by total output, $\bar{a}$ ) can be multiplied by the production effects that are derived from the Leontief inverse matrix or its modified version $\hat{L}$ (which also accounts for household activity by including an additional row and column of transactions) post-multiplied with a vector containing unitary increases for the synthetic industry (Equation (2)):

$$
M L T_{e, t, a s p e c t}^{\text {dir,indir,indu }}=\bar{a}(\boldsymbol{I}-\hat{A})^{-1} \Delta \boldsymbol{F}
$$

It is common practice among relevant studies that use I-O modelling to develop different types of multipliers. A comprehensive description of the basic algebra of their formulation and a detailed description regarding the computational procedure of several types of multipliers can be found in Miller and Blair's detailed manual on the subject [22].

\subsection{Definitions and Aggregations of Sectors}

Despite their practical usefulness in modeling economic impacts and changes in demand and production levels, the use of IOTs presents some limitations as well. For example, assessing the characteristics of a sector already present in an IOT is usually merely a matter of procedure, but when the economic activity of interest is either distributed across the already-existing sector or aggregated in a sector grouping, proper manipulations are required.

A common remedy is to perform the necessary disaggregation using additional information from external sources (usually in the form of detailed business satellite data), construct a new composite sector, and then recompile the modified tables into a closed I-O model. However, this can be quite an arduous and data-intensive procedure and is usually reserved for studies where the actual sector is the focal point of research interest $[26,41]$. For applications that are focused on comparative analyses rather than mapping production paths, some more efficient procedures can be followed, usually by utilizing the linearity assumption of I-O models.

The industries of interest for the present paper are related to RES, traditional energy production, and relevant industries. In detail, RESs include solar (mainly in the form of photovoltaic installations (PVs) and wind, hydro, geothermal, and biomass plants (although geothermal potential is rather limited in Greece) and supporting activities that are necessary for them to operate (suppliers of inputs and services). Traditional energy production refers to power generation from oil, gas, and lignite and their ecosystem (nuclear is excluded as there are neither such plants in operation in Greece nor any plans for them in the foreseeable future).

\subsection{Modeling Investment in RES Producing Sectors}

Due to their nature, the sectors that are involved in energy production for all types are spread across, already present in most available IOTs. This is a well-known obstacle, especially for the case of RES industries, and many studies have attempted to overcome it by separating them from the rest of the economy. The present study differs from this approach for the reasons mentioned in the previous section, and instead follows an alternative approach based on the distribution of investment in RESs in already-existing IOTs through the use of properly weighted demand vectors following the "synthetic industry" approach by Garrett-Peltier [30]. This approach can act as a preliminary assessment tool, and since the distribution is the only variable factor in the analysis, it is suited for comparative studies. Furthermore, since it follows structural changes induced by increases in demand, it can accommodate many spending types.

The actual weighting information contained in those demand vectors can be extracted by a variety of sources and vary in its description of the same industry. For example, this information can be compiled from extensive field surveys on firms, expert reports, theoretical categorization, or sometimes-when no alternative is present-assumptions about the placement of industries in the IOTs. We construct our demand vectors drawing on a diverse sample of studies previously utilized by [30]. The demand vectors, along with the relevant sources, are presented in the following Table 4. 
Table 4. Distribution of weights for the formation of demand vectors for the composite industries.

\begin{tabular}{|c|c|c|c|c|c|c|c|c|c|c|c|c|c|c|c|c|c|c|}
\hline \multicolumn{2}{|r|}{ Energy Industry } & \multicolumn{4}{|c|}{ Wind } & \multicolumn{5}{|c|}{ Solar } & \multirow{2}{*}{$\begin{array}{c}\text { Bioenergy } \\
{[42,43]}\end{array}$} & \multirow{2}{*}{$\begin{array}{c}\text { Hydro } \\
{[43]}\end{array}$} & \multicolumn{2}{|c|}{ Geothermal } & \multicolumn{2}{|c|}{ Oil and Gas } & \multicolumn{2}{|c|}{ Lignite } \\
\hline $\begin{array}{l}\text { Parent } \\
\text { Code }\end{array}$ & Subcategory & {$[42,43]$} & [44] & [45] & {$[30]$} & [42] & [43] & [30] & {$[46]$} & [47] & & & [42] & [30] & [42] & [43] & [42] & [43] \\
\hline A01 & Farm products & & & & & & & & & & 0.25 & & & & & & & \\
\hline A03 & Forestry, fishing, etc. & & & & & & & & & & 0.25 & & & & & & & \\
\hline B & $\begin{array}{l}\text { Oil, gas, lignite extraction, and } \\
\text { supporting activities }\end{array}$ & & & & & & & & & & & & 0.15 & 0.39 & 0.34 & 0.50 & 0.52 & 0.50 \\
\hline C19 & Petroleum/lignite products & & & & & & & & & & & & & & 0.53 & 0.25 & 0.48 & 0.50 \\
\hline $\mathrm{C} 20$ & Chemicals & & & & & & & & & & 0.125 & & & & & & & \\
\hline $\mathrm{C} 22$ & Plastics and rubber & 0.12 & & & & & & & & & & & & & & & & \\
\hline $\mathrm{C} 25$ & Fabricated metal products & 0.12 & 0.16 & 0.16 & 0.34 & 0.175 & 0.175 & 0.41 & 0.21 & 0.20 & & 0.18 & & 0.14 & & & & \\
\hline $\mathrm{C} 26$ & Computers/electronics & 0.03 & & & & 0.175 & 0.175 & & 0.385 & & & & & & & & & \\
\hline $\mathrm{C} 27$ & Electrical equipment & 0.03 & 0.15 & 0.314 & 0.34 & 0.175 & & 0.33 & 0.122 & 0.25 & & 0.14 & & 0.08 & & & & \\
\hline $\mathrm{C} 28$ & Machinery/equipment & 0.37 & 0.37 & & & & 0.175 & & & & & 0.07 & 0.10 & & & & & \\
\hline D35 & Natural gas distribution & & & & & & & & & & & & & & 0.10 & & & \\
\hline $\mathrm{F}$ & Construction & 0.26 & 0.20 & 0.276 & 0.255 & 0.30 & 0.30 & 0.095 & 0.125 & 0.29 & 0.25 & 0.18 & 0.45 & 0.25 & & & & \\
\hline $\mathrm{H} 49$ & Pipeline transportation & & 0.03 & & & & & & & & & & & & 0.03 & 0.25 & & \\
\hline K65 & Insurance and rel. activities & & 0.03 & & & & & & & & & & & & & & & \\
\hline M69-70 & Management/consulting activities & & 0.01 & & 0.025 & & & 0.025 & & 0.05 & & & & 0.07 & & & & \\
\hline M72 & Scientific and technical services & 0.07 & 0.02 & 0.09 & 0.04 & 0.175 & 0.175 & 0.02 & 0.109 & 0.21 & 0.125 & 0.43 & 0.30 & 0.07 & & & & \\
\hline & Sum of weights & 1 & 1 & 1 & 1 & 1 & 1 & 1 & 1 & 1 & 1 & 1 & 1 & 1 & 1 & 1 & 1 & 1 \\
\hline
\end{tabular}

Sources: [30,42-47]. 


\section{Results and Discussion}

\subsection{Estimates of New Investment and Sensitivity to Demand Vectorization Structure}

Our first results (shown below in Table 5) are concerned with obtaining the amount of necessary new investment in each RES type to achieve the planed energy production mix as described in Section 3.1. Our estimation (EUR 8.91 billion) for the total investment cost (for all types and periods) is aligned with the Greek NECP (which provisions EUR 9 billion). The difference can be attributed to the estimation procedure and different cost structure allocation of each RES type (e.g., amount of solar cost that corresponds to parks installation vs. storage).

Table 5. Estimates of new investment cost per RES type and time period.

\begin{tabular}{cccccc}
\hline & \multicolumn{5}{c}{$\Delta \mathbf{C}_{\mathrm{e}, \mathrm{t}}$ (in EUR Million) } \\
& $\mathbf{2 0 2 0 - 2 0 2 2}$ & $\mathbf{2 0 2 2 - 2 0 2 5}$ & $\mathbf{2 0 2 5 - 2 0 2 7}$ & $\mathbf{2 0 2 7 - 2 0 3 0}$ & $\mathbf{2 0 2 0 - 2 0 3 0}$ \\
\hline Bioenergy & 0 & 0 & 385 & 385 & $\mathbf{7 7 0}$ \\
Hydro & 570 & 190 & 190 & 0 & $\mathbf{9 5 0}$ \\
Wind & 352 & 653 & 387 & 449 & $\mathbf{1 8 4 0}$ \\
Solar (PVs) & 1152 & 1751 & 887 & 1218 & $\mathbf{5 0 0 8}$ \\
Geothermal & 0 & 0 & 0 & 340 & $\mathbf{3 4 0}$ \\
Total & $\mathbf{2 0 7 4}$ & $\mathbf{2 5 9 4}$ & $\mathbf{1 8 4 9}$ & $\mathbf{2 3 9 2}$ & $\mathbf{8 9 0 8}$ \\
\hline
\end{tabular}

Source: Authors' calculation based on the Greek NECP [5].

Next, we estimate the multiplier effects for the economy that are derived from a unitary increase in the demand for the output of the synthetic industries that can deploy each RES (and non-RES) energy type based on the demand vectors from Table 4, the latest available Greek IOT, and additional socioeconomic data, such as job positions, value added, and capital formation per sector, as described in Section 3.2.

The selection of a specific demand vector structure does not seem to considerably affect the estimation outcome, but its effect is still significant. The largest disparities in terms of standard deviation of a particular effect type, as shown in Table 6, are observed for the total contribution of geothermal (0.183) and solar (0.110) to value added, with all other coefficients for this aspect being below 0.1. This trend is repeated for geothermal; for example, for pretax wages, the largest value is again related to the total contribution of geothermal $(0.081)$ with all other values being below 0.05 , while for job creation, its total contribution presents four units of SD, the highest observed. However, since both the expected generation capacity and the expected investment for geothermal plants are almost negligible for Greece's power mix and other types of RES do not differ significantly in other aspects, we can confidently proceed with averaging each synthetic industry effect. The values for FFs are also very low, with only the SD of the total contribution of oil and gas on employment (3.1) appearing on top of the largest SD values per aspect (all others belong to RESs).

Table 6. Standard deviation metrics of demand vector multiplier effects.

\begin{tabular}{ccccccc}
\hline & & Wind & Solar & Geothermal & Oil and Gas & Lignite \\
\hline \multirow{3}{*}{ Value added } & Direct & 0.030 & 0.050 & 0.084 & 0.028 & 0.001 \\
& Indirect & 0.030 & 0.038 & 0.046 & 0.001 & 0.002 \\
& Induced & 0.016 & 0.026 & 0.052 & 0.015 & 0.001 \\
& Total & $\mathbf{0 . 0 7 4}$ & $\mathbf{0 . 1 1 0}$ & $\mathbf{0 . 1 8 3}$ & $\mathbf{0 . 0 4 2}$ & $\mathbf{0 . 0 0 4}$ \\
\hline \multirow{3}{*}{ Wages } & Direct & 0.011 & 0.021 & 0.044 & 0.015 & 0.000 \\
& Indirect & 0.008 & 0.011 & 0.017 & 0.002 & 0.001 \\
& Induced & 0.006 & 0.010 & 0.020 & 0.006 & 0.000 \\
& Total & $\mathbf{0 . 0 2 5}$ & $\mathbf{0 . 0 4 1}$ & $\mathbf{0 . 0 8 1}$ & $\mathbf{0 . 0 2 3}$ & $\mathbf{0 . 0 0 1}$ \\
\hline \multirow{3}{*}{ Employment } & Direct & 0.534 & 1.291 & 1.248 & 2.244 & 0.003 \\
& Indirect & 0.570 & 0.906 & 1.511 & 0.509 & 0.045 \\
& Induced & 0.393 & 0.641 & 1.277 & 0.355 & 0.017 \\
\hline
\end{tabular}


Table 6. Cont.

\begin{tabular}{ccccccc}
\hline & & Wind & Solar & Geothermal & Oil and Gas & Lignite \\
\hline \multirow{2}{*}{$\begin{array}{c}\text { Taxes less subsidies on } \\
\text { production and }\end{array}$} & Direct & 0.002 & 0.003 & 0.005 & 0.003 & 0.000 \\
products & Indirect & 0.003 & 0.004 & 0.004 & 0.000 & 0.000 \\
& Induced & 0.001 & 0.002 & 0.004 & 0.001 & 0.000 \\
& Total & $\mathbf{0 . 0 0 5}$ & $\mathbf{0 . 0 0 9}$ & $\mathbf{0 . 0 1 2}$ & $\mathbf{0 . 0 0 4}$ & $\mathbf{0 . 0 0 1}$ \\
\hline \multirow{2}{*}{ Gross fixed capital } & Direct & 0.107 & 0.149 & 0.264 & 0.018 & 0.001 \\
formation & Indirect & 0.003 & 0.010 & 0.019 & 0.018 & 0.000 \\
& Induced & 0.001 & 0.002 & 0.005 & 0.001 & 0.000 \\
& Total & $\mathbf{0 . 1 0 6}$ & $\mathbf{0 . 1 5 8}$ & $\mathbf{0 . 2 8 7}$ & $\mathbf{0 . 0 0 1}$ & $\mathbf{0 . 0 0 1}$
\end{tabular}

Notes: RES types with one or duplicate demand vectorization in the literature are omitted. All notes from Table 7 also apply here.

\subsection{Examination of Multiplier Effects}

Averaging the energy types that have more than one possible vector composition, we observe from Table 7 that, in general, the different RES types do not differ drastically in terms of their contribution to value added, wages paid to employees, and overall job creation. For example, spending EUR 1 million on the output of the synthetic industry that will deploy solar PV power generation capacity is expected to create about EUR $690 \mathrm{k}$ in the value added of the general economy (EUR $29 \mathrm{k}$ in direct contribution, EUR $25 \mathrm{k}$ in indirect, and EUR $16 \mathrm{k}$ in induced), which is almost the same as spending that amount in wind capacity (EUR $660 \mathrm{k}-$ EUR $26 \mathrm{k}$ in direct contribution, EUR $26 \mathrm{k}$ in indirect, and EUR $15 \mathrm{k}$ in induced). The results are similar for bioenergy plants (EUR $700 \mathrm{k}$ value added total) and geothermal (EUR $720 \mathrm{k}$ value added total) and quite a bit higher for hydro plants (EUR $910 \mathrm{k}$ value added total, the highest observed). The same trends and relative placement are also observed for contribution to pretax wages paid out to employees in each synthetic industry.

In terms of employment, bioenergy deployment has the greatest direct effect on job creation (10.4 jobs for each EUR 1 million spent on its output), while hydro is marginally first in terms of total job creation ( 20 jobs for each EUR 1 million- 8.3 in direct contribution, 6.1 in indirect, and 5.6 in induced). Bioenergy shows the same total job creation potential (19.1 jobs total), while geothermal shows a somewhat lower potential, at 17.8 jobs total, and the two remaining types (solar PVs and wind) come at the last place with 16.7 total jobs each.

The highest potential for investment attraction belongs to hydro, which shows by far the greatest multiplier effect (i.e., roughly $50 \%$ of the additional spending in the output of its corresponding synthetic industry will return to the economy in the form of direct contribution to the gross formation of capital assets (GFCF), while it also presents the highest total contribution. Geothermal energy presents a total multiplier effect of 0.45 , almost all of which (0.39) originating in direct form; this also stands for all RES types. Wind and solar have about the same contribution to GFCF with EUR $400 \mathrm{k}$ per EUR 1 million, and bioenergy returns the lowest total amount at EUR $310 \mathrm{k}$ per EUR 1 million.

The effects per type on taxes and subsidies on production and products of the synthetic industries that are earned and spent by the state are quite low to be worthy of detailed explanation or investigation (in the range of EUR 20-50 k per million euro). For the remainder of this paper, they are incorporated with the effects on value added to form the effects on gross domestic product (GDP). The relative similarity of these structural multiplier effects should not distract from the proportional scaling of their differences for large-enough investment amounts; for example, allocating EUR 1 million to the deployment of hydro and wind would result in a difference of generated value added of about a quarter million euro between them, based on their total structural multiplier effect ( 0.91 vs. 0.66 ). 


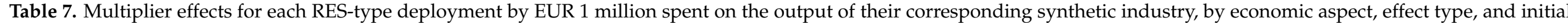
demand vector formation from the literature.

\begin{tabular}{|c|c|c|c|c|c|c|c|c|c|c|c|c|c|c|c|c|c|c|c|c|c|}
\hline \multirow[t]{2}{*}{ Composite Industry } & \multirow[t]{2}{*}{ Source } & \multicolumn{4}{|c|}{ Value Added } & \multicolumn{4}{|c|}{ Wages * } & \multicolumn{4}{|c|}{ Employment $* *$} & \multicolumn{4}{|c|}{$\begin{array}{c}\text { Taxes Less Subsidies on Production } \\
\text { and Products } * * *\end{array}$} & \multicolumn{4}{|c|}{ Gross Fixed Capital Formation } \\
\hline & & Dir. & Indi. & Indu. & Tot. & Dir. & Indi. & Indu. & Tot. & Dir. & Indi. & Indu. & Tot. & Dir. & Indi. & Indu. & Tot. & Dir. & Indi. & Indu. & Tot. \\
\hline \multirow{4}{*}{ Wind } & {$[42,43]$} & 0.24 & 0.23 & 0.14 & 0.61 & 0.09 & 0.07 & 0.05 & 0.22 & 6.58 & 5.58 & 3.40 & 15.56 & 0.02 & 0.02 & 0.01 & 0.05 & 0.48 & 0.04 & 0.01 & 0.52 \\
\hline & [44] & 0.23 & 0.23 & 0.13 & 0.59 & 0.09 & 0.07 & 0.05 & 0.20 & 6.65 & 5.49 & 3.20 & 15.35 & 0.02 & 0.02 & 0.01 & 0.05 & 0.40 & 0.03 & 0.01 & 0.44 \\
\hline & [45] & 0.29 & 0.28 & 0.17 & 0.74 & 0.11 & 0.08 & 0.06 & 0.26 & 7.45 & 6.60 & 4.06 & 18.11 & 0.02 & 0.03 & 0.01 & 0.06 & 0.28 & 0.04 & 0.01 & 0.34 \\
\hline & [30] & 0.27 & 0.29 & 0.16 & 0.71 & 0.10 & 0.08 & 0.06 & 0.24 & 7.62 & 6.43 & 3.82 & 17.88 & 0.02 & 0.03 & 0.01 & 0.06 & 0.24 & 0.03 & 0.01 & 0.29 \\
\hline Avg. Wind & & 0.26 & 0.26 & 0.15 & 0.66 & 0.10 & 0.07 & 0.06 & 0.23 & 7.08 & 6.03 & 3.62 & 16.72 & 0.02 & 0.02 & 0.01 & 0.06 & 0.35 & 0.03 & 0.01 & 0.40 \\
\hline \multirow{4}{*}{ Solar } & [42] & 0.30 & 0.26 & 0.17 & 0.72 & 0.12 & 0.08 & 0.06 & 0.26 & 7.24 & 6.15 & 4.12 & 17.50 & 0.02 & 0.02 & 0.01 & 0.06 & 0.42 & 0.04 & 0.02 & 0.48 \\
\hline & {$[30]$} & 0.26 & 0.26 & 0.15 & 0.67 & 0.10 & 0.07 & 0.06 & 0.23 & 6.98 & 5.57 & 3.59 & 16.14 & 0.02 & 0.02 & 0.01 & 0.05 & 0.12 & 0.02 & 0.01 & 0.15 \\
\hline & [46] & 0.22 & 0.19 & 0.12 & 0.53 & 0.09 & 0.05 & 0.05 & 0.19 & 5.26 & 4.26 & 3.05 & 12.57 & 0.02 & 0.02 & 0.01 & 0.04 & 0.34 & 0.03 & 0.01 & 0.38 \\
\hline & [47] & 0.36 & 0.29 & 0.20 & 0.84 & 0.14 & 0.08 & 0.08 & 0.30 & 8.89 & 6.67 & 4.77 & 20.33 & 0.02 & 0.03 & 0.01 & 0.07 & 0.38 & 0.04 & 0.02 & 0.44 \\
\hline Avg. Solar & & 0.29 & 0.25 & 0.16 & 0.69 & 0.11 & 0.07 & 0.06 & 0.25 & 7.15 & 5.71 & 3.91 & 16.77 & 0.02 & 0.02 & 0.01 & 0.05 & 0.36 & 0.04 & 0.01 & 0.41 \\
\hline Bioenergy & {$[42,43]$} & 0.35 & 0.21 & 0.13 & 0.70 & 0.10 & 0.06 & 0.05 & 0.21 & 10.38 & 5.41 & 3.26 & 19.05 & 0.02 & 0.02 & 0.01 & 0.05 & 0.27 & 0.03 & 0.01 & 0.31 \\
\hline Hydro & [43] & 0.43 & 0.26 & 0.23 & 0.91 & 0.19 & 0.08 & 0.09 & 0.35 & 8.33 & 6.07 & 5.58 & 19.98 & 0.02 & 0.02 & 0.02 & 0.06 & 0.50 & 0.05 & 0.02 & 0.57 \\
\hline Geothermal & [42] & 0.37 & 0.28 & 0.20 & 0.85 & 0.15 & 0.08 & 0.08 & 0.32 & 8.58 & 7.11 & 4.98 & 20.67 & 0.03 & 0.03 & 0.01 & 0.07 & 0.58 & 0.06 & 0.02 & 0.65 \\
\hline Avg. RES & & 0.33 & 0.24 & 0.17 & 0.74 & 0.12 & 0.07 & 0.06 & 0.26 & 8.13 & 5.85 & 4.09 & 18.07 & 0.02 & 0.02 & 0.01 & 0.06 & 0.37 & 0.04 & 0.01 & 0.43 \\
\hline \multirow{2}{*}{ Oil and Gas } & [42] & 0.10 & 0.12 & 0.05 & 0.27 & 0.02 & 0.03 & 0.02 & 0.07 & 0.92 & 2.33 & 1.14 & 4.39 & 0.02 & 0.01 & 0.00 & 0.04 & 0.05 & -0.01 & 0.00 & 0.04 \\
\hline & [43] & 0.14 & 0.12 & 0.07 & 0.33 & 0.04 & 0.04 & 0.03 & 0.10 & 4.09 & 3.05 & 1.65 & 8.79 & 0.02 & 0.01 & 0.00 & 0.04 & 0.02 & 0.02 & 0.01 & 0.05 \\
\hline Avg. Oil and Gas & & 0.12 & 0.12 & 0.06 & 0.30 & 0.03 & 0.04 & 0.02 & 0.09 & 2.51 & 2.69 & 1.40 & 6.59 & 0.02 & 0.01 & 0.00 & 0.04 & 0.03 & 0.01 & 0.01 & 0.04 \\
\hline \multirow{2}{*}{ Lignite } & [42] & 0.03 & 0.08 & 0.03 & 0.14 & 0.01 & 0.02 & 0.01 & 0.04 & 0.12 & 1.58 & 0.63 & 2.32 & 0.01 & 0.01 & 0.00 & 0.02 & 0.04 & -0.01 & 0.00 & 0.03 \\
\hline & [43] & 0.04 & 0.08 & 0.03 & 0.14 & 0.01 & 0.02 & 0.01 & 0.04 & 0.12 & 1.64 & 0.65 & 2.41 & 0.01 & 0.01 & 0.00 & 0.02 & 0.04 & -0.01 & 0.00 & 0.04 \\
\hline Avg. Lignite & & 0.04 & 0.08 & 0.03 & 0.14 & 0.01 & 0.02 & 0.01 & 0.04 & 0.12 & 1.61 & 0.64 & 2.36 & 0.01 & 0.01 & 0.00 & 0.02 & 0.04 & -0.01 & 0.00 & 0.03 \\
\hline Avg. FF & & 0.08 & 0.10 & 0.04 & 0.22 & 0.02 & 0.03 & 0.02 & 0.06 & 1.31 & 2.15 & 1.02 & 4.48 & 0.02 & 0.01 & 0.00 & 0.03 & 0.04 & 0.00 & 0.00 & 0.04 \\
\hline Avg. Difference RES-FF & & 0.25 & 0.14 & 0.13 & 0.52 & 0.10 & 0.04 & 0.05 & 0.19 & 6.81 & 3.70 & 3.07 & 13.59 & 0.00 & 0.01 & 0.01 & 0.02 & 0.34 & 0.04 & 0.01 & 0.39 \\
\hline
\end{tabular}

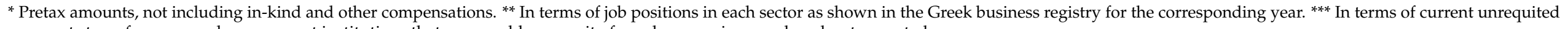
payments to or from general government institutions that are payable per unit of goods or services produced or transacted. 
Regarding fossil fuels, the contribution of their respective synthetic industries appears to be significantly smaller than any particular RES type. Lignite adds very little to GDP, with only EUR $160 \mathrm{k}$ per EUR 1 million in the value added of the general economy, most of which is an indirect contribution through the stimulation of other linked sectors (EUR $90 \mathrm{k}$ per EUR 1 million), while oil and gas present a significantly higher contribution at EUR $330 \mathrm{k}$ per EUR 1 million in total. This is true for all aspects of interest, with the closest these industries approach one another being in terms of total contribution to fixed assets formation (EUR $40 \mathrm{k}$ per EUR 1 million for oil and gas vs. EUR $30 \mathrm{k}$ for lignite), although it should be noted that the lignite synthetic industry has been exposed to significant deinvestment in the last years. Still, this means that the main "lost" potential when shifting away from fossil fuels in terms of deployment effects originates from oil and gas linkages in the economy rather than lignite. This is of importance, as while lignite generation capacity is to be completely phased out by 2028 and oil decreased by $84 \%$, gas generation capacity is to be increased by almost a third (33\%) to $6.9 \mathrm{GW}$ (Table 2).

\subsection{Overall Economic Effects Breakdown by Energy Type, Time Period, and Economic Aspect}

The averaged values per energy type from Table 6 along with the required cost estimations for Table 5 are combined to provide the detailed economic effects of total required investment breakdown by energy type, time period, economic aspect of interest, and effect type shown in Table 8. Overall, we estimate that the EUR 8.91 billion required for the implementation of the NECP's targets by 2030 will contribute EUR 6.83 billion to Greek GDP, EUR 2.25 billion to the compensation of involved employees in terms of their pretax wages, EUR 3.70 billion to the formation of fixed capital assets, and about $154 \mathrm{k}$ job positions in a 10-year frame (2020-2030). Our results are comparable but considerably lower than those provided by the Greek NECP (EUR 12.6 billion for domestic value added and EUR 4.8 billion for wages), a fact that mainly relates to the different methodological approaches and scope between the two studies, as NECP's results refer to the total lifespan of the investment, while we only account for their development phase during the 2020-2030 period.

In more detail, 55\% of the total contribution to GDP will originate from investments in PV installation, 19\% from wind, 14\% from hydro, and 12\% from bioenergy and geothermal plants, as can be visualized in Figure 2. This reflects the NECP's general planning for the energy mix per resource, where solar and wind are the main pillars of RES power generation, and is also mirrored in the effects on wages, employment, and capital formation (in all cases, about 55\% of the total contribution to each economic aspect will originate from PVs and 19\% from wind). Interestingly, the contribution of hydro is not only limited by the relatively less amount of spending for related plants but also by the lack of planning for additional capacity in 2027-2030. 
Table 8. Economic effects breakdown by energy type, time period, economic aspect of interest, and effect type (in mil €).

\begin{tabular}{|c|c|c|c|c|c|c|c|c|c|c|c|c|c|c|c|c|c|c|c|c|c|}
\hline & & \multicolumn{5}{|c|}{ GDP } & \multicolumn{5}{|c|}{ Wages * } & \multicolumn{5}{|c|}{ Employment ** } & \multicolumn{5}{|c|}{ GFCF } \\
\hline & & $\begin{array}{l}2020- \\
2022 \\
\end{array}$ & $\begin{array}{l}2022- \\
2025 \\
\end{array}$ & $\begin{array}{l}2025- \\
2027 \\
\end{array}$ & $\begin{array}{l}2027- \\
2030 \\
\end{array}$ & Tot. & $\begin{array}{l}2020- \\
2022 \\
\end{array}$ & $\begin{array}{l}2022- \\
2025 \\
\end{array}$ & $\begin{array}{l}2025- \\
2027 \\
\end{array}$ & $\begin{array}{l}2027- \\
2030 \\
\end{array}$ & Tot. & $\begin{array}{l}2020- \\
2022 \\
\end{array}$ & $\begin{array}{l}2022- \\
2025\end{array}$ & $\begin{array}{l}2025- \\
2027\end{array}$ & $\begin{array}{l}2027- \\
2030 \\
\end{array}$ & Tot. & $\begin{array}{l}2020- \\
2022 \\
\end{array}$ & $\begin{array}{l}2022- \\
2025 \\
\end{array}$ & $\begin{array}{l}2025- \\
2027 \\
\end{array}$ & $\begin{array}{l}2027- \\
2030\end{array}$ & Tot. \\
\hline \multirow{4}{*}{ Bioenergy } & Direct & 0 & 0 & 143.3 & 143.3 & 287 & 0 & 0 & 37 & 37 & 73 & 0 & 0 & 3998 & 3998 & 7995 & 0 & 0 & 103 & 103 & 206 \\
\hline & Indirect & 0 & 0 & 87.1 & 87.1 & 174 & 0 & 0 & 23 & 23 & 46 & 0 & 0 & 2082 & 2082 & 4164 & 0 & 0 & 13 & 13 & 25 \\
\hline & Induced & 0 & 0 & 54.9 & 54.9 & 110 & 0 & 0 & 20 & 20 & 40 & 0 & 0 & 1254 & 1254 & 2508 & 0 & 0 & 5 & 5 & 9 \\
\hline & Total & 0.0 & 0.0 & 285.3 & 285.3 & 571 & 0 & 0 & 80 & 80 & 159 & 0 & 0 & 7334 & 7334 & 14,667 & 0 & 0 & 120 & 120 & 240 \\
\hline \multirow{4}{*}{ Hydro } & Direct & 257 & 86 & 86 & 0 & 428 & 107 & 36 & 36 & 0 & 178 & 4748 & 1583 & 1583 & 0 & 7913 & 286 & 95 & 95 & 0 & 476 \\
\hline & Indirect & 160 & 53 & 53 & 0 & 266 & 45 & 15 & 15 & 0 & 75 & 3462 & 1154 & 1154 & 0 & 5771 & 28 & 9 & 9 & 0 & 47 \\
\hline & Induced & 139 & 46 & 46 & 0 & 232 & 50 & 17 & 17 & 0 & 84 & 3179 & 1060 & 1060 & 0 & 5299 & 12 & 4 & 4 & 0 & 19 \\
\hline & Total & 556 & 185 & 185 & 0 & 927 & 202 & 67 & 67 & 0 & 336 & 11,389 & 3796 & 3796 & 0 & 18,982 & 326 & 109 & 109 & 0 & 543 \\
\hline \multirow{4}{*}{ Wind } & Direct & 98 & 182 & 108 & 125 & 512 & 35 & 64 & 38 & 44 & 181 & 2492 & 4618 & 2736 & 3178 & 13024 & 123 & 228 & 135 & 157 & 643 \\
\hline & Indirect & 99 & 184 & 109 & 127 & 519 & 26 & 49 & 29 & 33 & 137 & 2122 & 3932 & 2329 & 2705 & 11,089 & 12 & 22 & 13 & 15 & 63 \\
\hline & Induced & 56 & 103 & 61 & 71 & 291 & 20 & 37 & 22 & 26 & 105 & 1275 & 2362 & 1400 & 1625 & 6662 & 5 & 9 & 5 & 6 & 24 \\
\hline & Total & 253 & 469 & 278 & 323 & 1323 & 81 & 150 & 89 & 103 & 423 & 5890 & 10,913 & 6465 & 7508 & 30,776 & 140 & 259 & 153 & 178 & 731 \\
\hline \multirow{4}{*}{ Solar } & Direct & 353 & 536 & 272 & 373 & 1534 & 132 & 201 & 102 & 140 & 574 & 8229 & 12,512 & 6340 & 8704 & 35,785 & 409 & 622 & 315 & 433 & 1779 \\
\hline & Indirect & 311 & 472 & 239 & 329 & 1351 & 83 & 126 & 64 & 87 & 359 & 6579 & 10,004 & 5069 & 6960 & 28,612 & 42 & 63 & 32 & 44 & 181 \\
\hline & Induced & 197 & 299 & 152 & 208 & 857 & 71 & 108 & 55 & 75 & 309 & 4503 & 6847 & 3469 & 4763 & 19,583 & 16 & 25 & 13 & 17 & 71 \\
\hline & Total & 860 & 1308 & 663 & 910 & 3742 & 286 & 434 & 220 & 302 & 1242 & 19,311 & 29,363 & 14,879 & 20,427 & 83,979 & 467 & 710 & 360 & 494 & 2032 \\
\hline \multirow{4}{*}{ Geothermal } & Direct & 0 & 0 & 0 & 114 & 114 & 0 & 0 & 0 & 42 & 42 & 0 & 0 & 0 & 2616 & 2616 & 0 & 0 & 0 & 134 & 134 \\
\hline & Indirect & 0 & 0 & 0 & 90 & 90 & 0 & 0 & 0 & 24 & 24 & 0 & 0 & 0 & 2053 & 2053 & 0 & 0 & 0 & 15 & 15 \\
\hline & Induced & 0 & 0 & 0 & 61 & 61 & 0 & 0 & 0 & 22 & 22 & 0 & 0 & 0 & 1387 & 1387 & 0 & 0 & 0 & 5 & 5 \\
\hline & Total & 0 & 0 & 0 & 265 & 265 & 0 & 0 & 0 & 88 & 88 & 0 & 0 & 0 & 6056 & 6056 & 0 & 0 & 0 & 153 & 153 \\
\hline
\end{tabular}

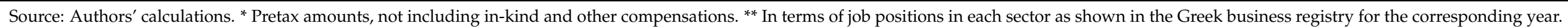




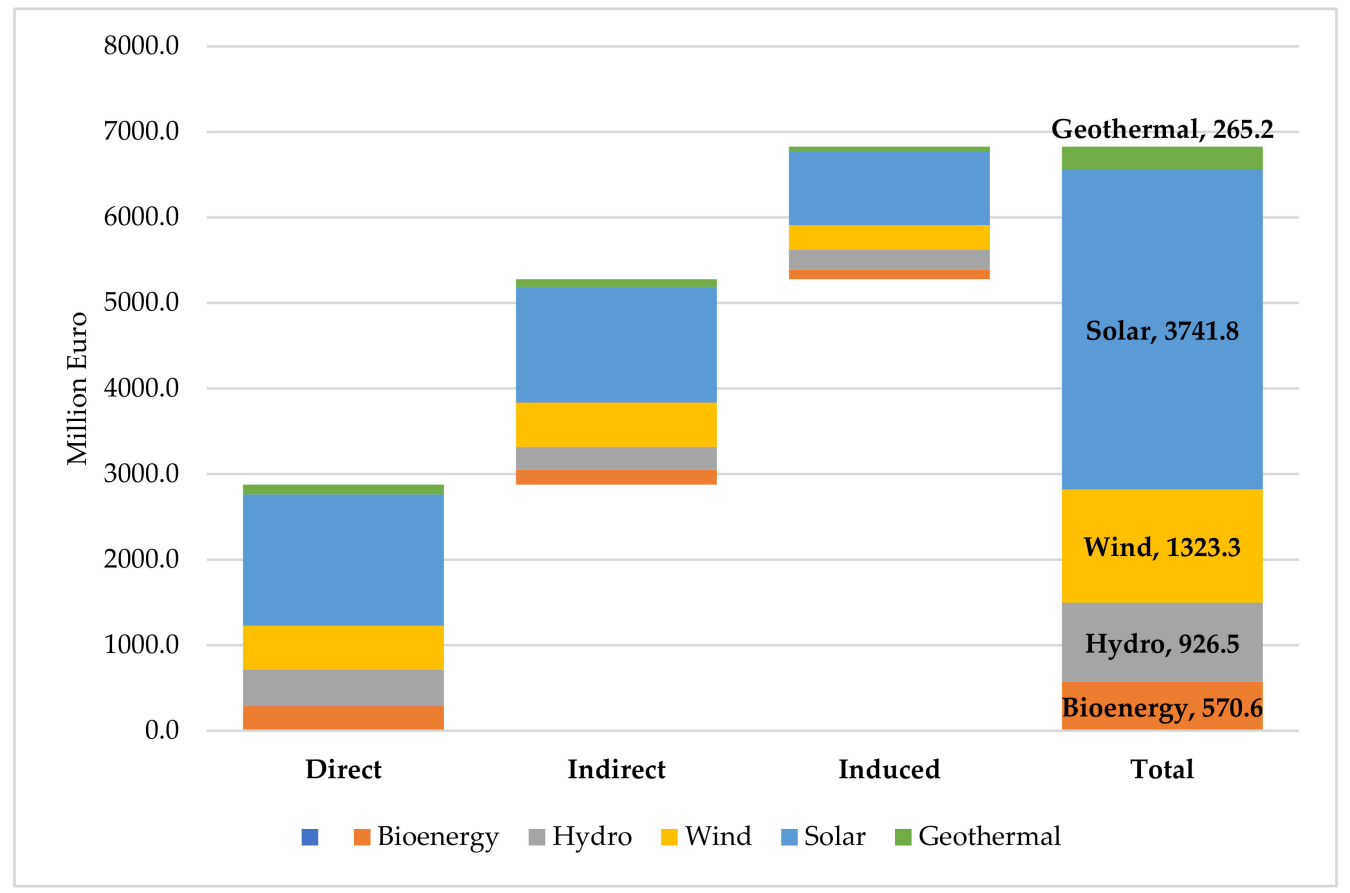

Figure 2. Breakdown of total contribution to GDP from RES deployment per type.

\section{Conclusions and Policy Implications}

The present paper showcases the potential for economic benefits that can be achieved through the planned investment in RES interventions in Greece. First, we obtain the required investment amounts per RES type from installation capacity costs from the Greek NECP and combine them with appropriate demand vectors, and then we integrate them within the I-O framework to estimate the structural (multiplier) effects for value added, employment, wages, and investment in the Greek economy.

Overall, we estimate that the EUR 8.91 billion required for the implementation of the NECP's targets by 2030 will contribute EUR 6.83 billion to Greek GDP, EUR 2.25 billion to the compensation of involved employees in terms of their pretax wages, EUR 3.70 billion to the formation of fixed capital assets, and approximately $154 \mathrm{k}$ job positions in a 10-year frame (2020-2030). These effects are mainly driven by investments in solar and wind power generation. Furthermore, the positive multiplier effects of the RES investment plan appear to have the necessary magnitude to nullify any negative effects due to reduced subsidies and support for FF power generation. Therefore, the more ambitious targets set in Greece's revised energy and climate plan (NECP 2019, [5]) in terms of further RES penetration in the energy mix appear to be well oriented and set to provide structural economic benefits to the economy.

Our analysis was conducted based on an I-O modelling application, which qualifies as a suitable tool for the quantification of the structural impact of policy interventions in the economy. However, I-O modelling, and by extension our approach, is subjected to some inherent limitations that relate to the linearity of the $\mathrm{I}-\mathrm{O}$ model and the static nature of IOTs, resulting in the use of past data (namely, the 2015 Greek IOT) to depict the production linkages of the Greek economy. Furthermore, this study focuses on the multiplier effects that derive from the use of these investments for the installation of facilities and relevant infrastructures for RESs and not their future operation. Additional exogenous factors that need to be considered when examining the results of this study further include the fluctuations of energy prices and their ramifications on energy markets as well the elasticity among different types of energy supply. Future research should focus on tackling these deficiencies by incorporating the operational aspects of this investment plan, further expand the approach to monitor the structural effects of energy efficiency interventions, 
and also integrate the regional aspect into the framework, to examine different scenarios that relate to the location of these facilities and the implications for the local economies. This includes investigations of the nature of jobs that are created (from RES investment) and lost (from phasing out carbon-intensive power generation industries) and the dependence of this relationship on other factors, such as the demographic characteristics and the state of the job market in the affected regions. Another opportunity for future research would be to apply an appropriately modified methodological version of the present paper to study the structural effects of investment in supporting activities in terms of grid improvements, efficiency, and weatherization, which are often co-pursued with RES investment.

An important implication of this study is that it highlights that the need for better communication of initiatives that relate to the development of RES is as important as the transition to decarbonization. The required activities for the construction and maintenance as well the regular operation of large-scale RES infrastructures have the potential to create not only more employment opportunities but also additional economic value and environmental benefits for the regions they are implemented in. However, there is a persistent perception that the transition to RES is translated to negative employment and economic effects, particularly in regions or countries where coal industries have traditionally been regarded as major providers of "safe" employment, leading to a significant underestimation of their economic benefits but also of the detrimental health effects they cause. This is linked to some broader issues regarding the relationship between the political characteristics of countries and the state of their energy market and power generation design. It is therefore critical that the expected economic benefits of investing in RES are effectively and properly communicated to relevant stakeholders and the general public to provide solid arguments that go beyond health benefits and touch on their overall social and economic welfare.

Author Contributions: Conceptualization, D.S. and P.D.; methodology, D.S.; software, D.S.; formal analysis, P.D. and D.S.; data curation, D.S. and P.D.; resources, I.S.; writing—original draft preparation, D.S. and P.D.; writing-review and editing, I.S. and A.T.; supervision, I.S. and A.T. All authors have read and agreed to the published version of the manuscript.

Funding: Funding for this research was received from the European Union's (EU) LIFE program under the Grant Agreement LIFE17 IPC/GR/000006: “Project LIFE-IP AdaptInGR-Boosting the implementation of adaptation policy across Greece" and the Green Fund of Greece. The text reflects only the authors' views, and the European Union is not liable for any use that may be made of the information contained therein.

Data Availability Statement: All primary data used are openly available online with sources in English. The latest (2015) symmetrical input-output table for Greece can be retrieved here: https: //www.statistics.gr/en/statistics/-/publication/SEL38/2015 (accessed on 5 October 2021). The Statistical Business Registry for Greece can be retrieved here: https: / www.statistics.gr/bussines registries (accessed on 5 October 2021). The Greek National Energy and Climate Plan from which the data regarding RES capacity, operation, planned expansion, and deployment cost were drawn can be retrieved here: https:/ / ec.europa.eu/energy/sites / default/files/el_final_necp_main_en.pdf (accessed on 2 September 2021). Links are confirmed to be valid at the time of writing.

Conflicts of Interest: The authors declare no known conflict of interest to disclose.

\section{References}

1. IPCC. Summary for Policymakers. In Climate Change 2021: The Physical Science Basis; Contribution of Working Group I to the Sixth Assessment Report of the Intergovernmental Panel on Climate Change; Masson-Delmotte, V., Zhai, P., Pirani, A., Connors, S.L., Péan, C., Berger, S., Caud, N., Chen, Y., Goldfarb, L., Gomis, M.I., Eds.; Cambridge University Press: Cambridge, UK, 2021.

2. Sebos, I.; Progiou, A.; Kallinikos, L.; Eleni, P.; Katsavou, I.; Mangouta, K.; Ziomas, I. Mitigation and Adaptation Policies Related to Climate Change in Greece. In Energy, Transportation and Global Warming. Green Energy and Technology; Grammelis, P., Ed.; Springer: Cham, Switzerland, 2016; pp. 35-49. [CrossRef]

3. EEA. Submission under the United Nations Framework Convention on Climate Change and the Kyoto Protocol. EEA Report No 5/2021. Copenhagen, Denmark. Available online: https://www.eea.europa.eu/publications/annual-european-uniongreenhouse-gas-inventory-2021 (accessed on 1 November 2021). 
4. Regulation (EU) 2018/1999 of the European Parliament and of the Council of 11 December 2018 on the Governance of the Energy Union and Climate Action; Publications Office: Luxembourg, 2018.

5. Hellenic Republic, Ministry of the Environment and Energy, MEEN. The National Energy and Climate Plan (NECP). 2019. Available online: https://ec.europa.eu/info/energy-climate-change-environment/implementation-eu-countries/energy-andclimate-governance-and-reporting/national-energy-and-climate-plans_en (accessed on 20 September 2021).

6. Wei, M.; Patadia, S.; Kammen, D.M. Putting renewables and energy efficiency to work: How many jobs can the clean energy industry generate in the US? Energy Policy 2010, 38, 919-931. [CrossRef]

7. Markaki, M.; Belegri-Roboli, A.; Michaelides, P.; Mirasgedis, S.; Lalas, D.P. The Impact of Clean Energy Investments on the Greek Economy: An Input-Output Analysis (2010-2020). Energy Policy 2013, 57, 263-275. [CrossRef]

8. Moreno, B.; López, A.J. The Effect of Renewable Energy on Employment. The Case of Asturias (Spain). Renew. Sustain. Energy Rev. 2008, 12, 732-751. [CrossRef]

9. Jenniches, S. Assessing the regional economic impacts of renewable energy sources-A literature review. Renew. Sustain. Energy Rev. 2018, 93, 35-51. [CrossRef]

10. De Arce, R.; Mahía, R.; Medina, E.; Escribano, G. A simulation of the economic impact of renewable energy development in Morocco. Energy Policy 2012, 46, 335-345. [CrossRef]

11. Heavner, B.; Del Chiaro, B. Renewable Energy and Jobs: Employment Impacts of Developing Markets for Renewables in California; Environment California Research and Policy Center: Sacramento, CA, USA, 2003.

12. Simons, G.; Peterson, T. California Renewable Technology Market and Benefits Assessment; Electric Power Research Institute (EPRI): Washington, DC, USA; California Energy Commission (CEC): Sacramento, CA, USA, 2001.

13. Fang, Y. Economic welfare impacts from renewable energy consumption: The China experience. Renew. Sustain. Energy Rev. 2011, 15, 5120-5128. [CrossRef]

14. Apergis, N.; Payne, J.E. Renewable energy consumption and economic growth: Evidence from a panel of OECD countries. Energy Policy 2010, 38, 656-660. [CrossRef]

15. Inglesi-lotz, R. The impact of renewable energy consumption to economic growth: A panel data application. Energy Econ. 2016, 53, 58-63. [CrossRef]

16. Dogan, E.; Altinoz, B.; Madaleno, M.; Taskin, D. The impact of renewable energy consumption to economic growth: A replication and extension of Inglesi-Lotz (2016). Energy Econ. 2020, 90, 104866. [CrossRef]

17. Menegaki, A.N. growth and renewable energy in Europe: A random effect model with evidence for neutrality hypothesis. Energy Econ. 2011, 33, 257-263. [CrossRef]

18. Saint Akadiri, S.; Alola, A.A.; Akadiri, A.C.; Alola, U.V. Renewable energy consumption in EU-28 countries: Policy toward pollution mitigation and economic sustainability. Energy Policy 2019, 132, 803-810. [CrossRef]

19. Armeanu, D.Ş.; Vintilă, G.; Gherghina, Ş.C. Does Renewable energy drive sustainable economic growth? Multivariate panel data evidence for EU-28 countries. Energies 2017, 10, 381. [CrossRef]

20. Simionescu, M.; Strielkowski, W.; Tvaronavičienè, M. Renewable energy in final energy consumption and income in the EU-28 countries. Energies 2020, 13, 2280. [CrossRef]

21. Sahlian, D.N.; Popa, A.F.; Creţu, R.F. Does the increase in renewable energy influence gdp growth? An EU-28 analysis. Energies 2021, 14, 4762. [CrossRef]

22. Ntanos, S.; Skordoulis, M.; Kyriakopoulos, G.; Arabatzis, G.; Chalikias, M.; Galatsidas, S.; Batzios, A.; Katsarou, A. Renewable energy and economic growth: Evidence from european countries. Sustainability 2018, 10, 2626. [CrossRef]

23. Marinaș, M.-C.; Dinu, M.; Socol, A.-G.; Socol, C. Renewable energy consumption and economic growth. Causality relationship in central and eastern european countries. PLoS ONE 2018, 13, e0202951. [CrossRef] [PubMed]

24. Bloch, H.; Rafiq, S.; Salim, R. Economic growth with coal, oil and renewable energy consumption in China: Prospects for fuel substitution. Econ. Model. 2015, 44, 104-115. [CrossRef]

25. Rafindadi, A.A.; Ozturk, I. Impacts of renewable energy consumption on the german economic growth: Evidence from Combined cointegration test. Renew. Sustain. Energy Rev. 2017, 75, 1130-1141. [CrossRef]

26. Miller, R.E.; Blair, P.D. Input-Output Analysis: Foundations and Extensions, 2nd ed.; Cambridge University Press: Cambridge, UK, 2009.

27. Tourkolias, C.; Mirasgedis, S. Quantification and monetization of employment benefits associated with renewable energy technologies in Greece. Renew. Sustain. Energy Rev. 2011, 15, 2876-2886. [CrossRef]

28. Scott, M.J.; Roop, J.; Schultz, R.; Anderson, D.; Cort, K. The impact of DOE building technology energy efficiency programs on US employment, income, and investment. Energy Econ. 2008, 30, 2283-2301. [CrossRef]

29. Kuckshinrichs, W.; Kronenberg, T.; Hansen, P. The social return on investment in the energy efficiency of buildings in Germany. Energy Policy 2010, 38, 4317-4329. [CrossRef]

30. Garrett-Peltier, H. Green versus brown: Comparing the employment impacts of energy efficiency, renewable energy, and fossil fuels using an input-output model. Econ. Model. 2017, 61, 439-447. [CrossRef]

31. Malik, A.; Lenzen, M.; Ely Rô, N.; Dietzenbacher, E. Simulating the impact of new industries on the economy: The case of biorefining in Australia. Ecol. Econ. 2014, 107, 84-93. [CrossRef]

32. Varela-Vázquez, P.; del Carmen Sánchez-Carreira, M. Estimation of the potential effects of offshore wind on the spanish economy. Renew. Energy 2017, 111, 815-824. [CrossRef] 
33. Keček, D.; Mikulić, D.; Lovrinčević, Ž. Deployment of renewable energy: Economic effects on the croatian economy. Energy Policy 2019, 126, 402-410. [CrossRef]

34. Wade, J.; Warren, A. Employment Generation from Energy Efficiency Programmes: Enhancing Political and Social Acceptability. In Proceedings of the ACEEE Summer Study on Energy Efficiency in Industry, Tarrytown, NY, USA, 24-27 July 2001. Available online: https://www.eceee.org/library/conference_proceedings/eceee_Summer_Studies/2001/Panel_1/p1_7/ (accessed on 11 November 2021).

35. Regulation (EU) No 549/2013 of the European Parliament and of the Council of 21 May 2013 on the European System of National and Regional Accounts in the European Union; Publications Office of the European Union: Luxembourg, 2013.

36. Allan, G.; Mcgregor, P.; Swales, K. The Importance of Revenue Sharing for the Local Economic Impacts of a Renewable Energy Project: A Social Accounting Matrix Approach. Reg. Stud. 2011, 45, 1171-1186. [CrossRef]

37. Mainar-Causapé, A.J.; Ferrari, E.; McDonald, S. Social Accounting Matrices: Basic Aspects and Main Steps for Estimation; EUR 29297 EN, JRC Technical Reports ; Publications Office of the European Union: Luxembourg, 2018. [CrossRef]

38. Guo, Z.; Zhang, X.; Zheng, Y.; Rao, R. Exploring the Impacts of a Carbon Tax on the Chinese Economy Using a CGE Model with a Detailed Disaggregation of Energy Sectors. Energy Econ. 2014, 45, 455-462. [CrossRef]

39. Guo, Z.; Zhang, X.; Feng, S.; Zhang, H. The impacts of reducing renewable energy subsidies on China's energy transition by using a hybrid dynamic computable general equilibrium model. Front. Energy Res. 2020, 8, 25. [CrossRef]

40. Leontief, W. Input-Output Economics, 2nd ed.; Oxford University Press: New York, NY, USA, 1986.

41. Tsakanikas, A.; Dimas, P.; Stamopoulos, D. The Greek ICT Sector and Its Contribution to Innovation and Economic Growth. In Modeling Economic Growth in Contemporary Greece; Vlachos, V., Bitzenis, A., Sergi, B.S., Eds.; Emerald Publishing Limited: Bingley, UK, 2021; pp. 281-300. [CrossRef]

42. Garrett-Peltier, H. Creating a Clean-Energy Economy: How Investments in Renewable Energy and Energy Efficiency Can Create Jobs in a Sustainable Economy; Lambert Academic Publishing: Saarbrucken, Germany, 2011.

43. Pollin, R.; Garrett-Peltier, H.; Heintz, J.; Chakraborty, S. Global Green Growth: Clean Energy Industrial Investments and Expanding Job Opportunities; United Nations Industrial Development Organization: Vienna, Austria; Global Green Growth Institute: Seoul, Korea, 2015.

44. Tegen, S.; Hand, M.; Maples, B.; Lantz, E.; Schwabe, P.; Smith, A. 2011 Cost of Wind Energy Review; NREL Technical Report NREL/TP 5000-56266; National Renewable Energy Laboratory: Golden, CO, USA, 2013.

45. International Renewable Energy Agency (IRENA). Wind Power. In Renewable Energy Technologies: Cost Analysis Series; IRENA: Abu Dhabi, United Arab Emirates, 2012.

46. International Renewable Energy Agency (IRENA). Solar Photovoltaics. In Renewable Energy Technologies: Cost Analysis; IRENA: Abu Dhabi, United Arab Emirates, 2012.

47. Bloomberg New Energy Finance (BNEF). Sustainable Energy in America: 2013 Factbook; BNEF: New York, NY, USA, 2013. 